\title{
Coulisses
}

Revue de théâtre

5 | Hiver 1992

Varia

\section{Pierre Perrin, chasseur des mots-sillons}

Aline Dornier et Laurent Devanne

\section{OpenEdition}

Journals

Édition électronique

URL : http://journals.openedition.org/coulisses/1732

DOI : $10.4000 /$ coulisses. 1732

ISSN : 2546-9460

\section{Éditeur}

Presses universitaires de Franche-Comté

\section{Édition imprimée}

Date de publication : 1 janvier 1992

Pagination : 71-72

ISSN : 1150-594X

\section{Référence électronique}

Aline Dornier et Laurent Devanne, «Pierre Perrin, chasseur des mots-sillons », Coulisses [En ligne], 5 |

Hiver 1992, mis en ligne le 04 juillet 2017, consulté le 23 octobre 2019. URL : http://

journals.openedition.org/coulisses/1732 ; DOI : 10.4000/coulisses.1732

Ce document a été généré automatiquement le 23 octobre 2019

Coulisses 


\title{
Pierre Perrin, chasseur des mots- sillons
}

\author{
Aline Dornier et Laurent Devanne
}

\section{Présentation}

1 Si Pierre Perrin éprouve le besoin d'écrire dès son adolescence, au fond d'un séminaire, c'est pour mieux comprendre ses sentiments obscurs et complexes. C'est à l'âge de 19 ans qu'il se trouve véritablement face à la réalité de la mort :

«Père est mort, en mon absence... C'était à trembler. J'ai peut-être, pour la première fois, mesuré l'inconnu et l'incommensurable de la souffrance, quand elle traverse un être ».

La mort du père, in Le temps, c'est aujourd'hui.

2 L'écriture devient une thérapie, une échappatoire au suicide. "Les mots évitent le geste ». Ses vers sont alors cassés, évoquant le vide, l'angoisse qui le tenaillent, il voit son existence se décomposer sans qu'il puisse la reconstituer. La mort est au bout de tous les chemins qu'il emprunte, comme un irrémédiable obstacle :

«Il faut tout remettre au lendemain pour rebâtir et de nouveau céder ».

Un soleil défenestré, in Pleine marge.

3 Cependant «elle est à l'origine de toute création », comme si « la mort précédait la naissance ». Toute œuvre d'art s'érige comme un rempart entre l'homme et son angoisse existentielle. C'est sans doute pourquoi Pierre Perrin désire tant être publié et reconnu. En 1972, à l'âge de 22 ans, il publie ses premiers écrits qu'il intitule Pleine marge, ouvrage remarqué par Jean Breton dans Le magazine littéraire. Dans Chroniques d'absences, il écrit

« Le niveau de la mort cette nuit a monté...

J'écris cet « art poétique »

pour ne pas perdre pied

au milieu de mes os. »

4 Sans cesse, Pierre Perrin se révolte ouvertement contre la mort, jamais il ne dénonce le temps. Il semble regretter non pas que le temps détruise l'homme, mais que l'homme 
soit détruit par le temps. Le rêve du poète serait de "se reproduire à l'infini", d'atteindre une forme d'éternité. Il tente de réaliser ce désir à travers une double quête : celle de la célébrité posthume, même s'il la sait chimérique :

«Mes livres voudraient être des ponts que je lance sur la mort. »

Voyage sédentaire. transfigurer le quotidien, il oblige ceux qui s'aiment à se transformer pour donner le meilleur d'eux-mêmes. «L'amour, c'est le oui-clos » (Un voyage sédentaire). Dans les bras de la femme aimée, le poète renaît et invente avec elle la « démesure de vivre ». Comme Camus, il «veut être plus qu'un homme, c'est-à-dire un homme heureux ». Même si l'amour est souvent synonyme de souffrance, il demeure son ultime raison de vivre, sa seule espérance de bonheur : "Aimer, c'est donner toute la place à qui nous emporte. C'est grandir à deux, jouir en miroir et devenir une plénitude en orbite dans le bonheur ». Cet aphorisme tiré de Lumière et Poésie, est un véritable hymne à l'amour composé "à quatre mains", où la luminosité des tableaux de Lescoffit répond aux rayons de bonheur semés par Pierre Perrin.

7 Dans «ce monde fardé d'hypocrisie » ou "la fédération des états du monde n'est encore qu'un fœtus d'idéal » (préface de Lumière et Poésie), il veut rester authentique et sans être un guide, il souhaite simplement apporter le fruit de son expérience.

Comme Flaubert qu'il admire, il a besoin de retravailler ses textes pour rendre son style concis jusqu'à dire l'essentiel; ce qui va parfois à rencontre de son objectif, en particulier qui est de « rester direct, éminemment simple, accessible ».

«(...) J'écris pour moi, pour tous, Et si je reste vague, c'est affaire de houle, de manque de foule. Mais j'avance. La route est tracée. Je l'accrois pour que peut-être des enfants conquièrent leur droit au bonheur. »

Pourquoij'écris, in Le temps gagné.

9 Sa poésie respire l'intensité des émotions qu'il a vécues, en ce sens, son « œuvre devient un kaléidoscope de passions » (Un voyage sédentaire).

Yves Martin, son «maître à penser ", écrit en postface de Manque à vivre: Pierre Perrin se range dans la file des poètes du «dur métier de vivre ». Ainsi après être longtemps resté dans l'ombre de la mort, il a réussi à se « libérer en dominant ses passions. II a atteint une forme de sagesse lumineuse qui transparaît dans sa poésie plus limpide et plus généreuse ».

\section{BIBLIOGRAPHIE}

Manque à vivre, choix de poèmes 1969-1984, postface d'Yves Martin, Editions possibles 1985.

Lycée-Passions, roman, prix Louis Pergaud 1986, réédition corrigée en préparation. 
Un voyage sédentaire, notes (sur l'art, l'amour, la société...), éditions Possibles, 1986 et repris par la Bartavelle éditeur.

Sept poètes contemporains, introduction, choix et notices, revue Poésie 1 n 132 , décembre 1986.

Les cent plus beaux poèmes de Victor Hugo, préface et choix, Club France Loisirs, 1987.

Le Temps gagné, poèmes, éditions la Bartavelle, 1988.

La Bartavelle présente Pierre Perrin, études de l'œuvre par Jean Breton, Éric Ballandras, Jean Joubert, Luce Guilbaud, Éric Brogniet ; lettres de G. Mounin, J. Reda, J. Perol, A. Gerber ; ainsi que Des Bonheurs de Traverse, 15 inédits, 1989.

Lumière et Poésie, en collaboration avec le peintre Michel Lescoffit (42 reproductions couleur), Galeries St-Laurent éditeur, 1990.

Choses vues de Victor Hugo, préface et choix, éditions de la Vallée, 1990.

L'Enfant de la terre, roman, 1991.

\section{AUTEURS}

\section{ALINE DORNIER}

Étudiante

\section{LAURENT DEVANNE}

Étudiant 